\title{
Holographic Reconstruction of Objects in a Mixed-Reality, Post-Truth Era: A Personal Essay
}

\author{
Mary Harman \\ Independent Visual Artist, Montreal, QC H4A 2W3, Canada; mail@maryharman.com
}

Received: 27 May 2019; Accepted: 5 August 2019; Published: 16 August 2019

\begin{abstract}
The ephemeral holographic image is an appropriate medium to express the nature of reality and illusion, an early interest I explored with trompe-l'œil painting. To make a representational hologram, one needs a worthy object to copy, and one that is hand-made by the artist adds to the unity of the work. The resulting copy physically resembles the original, and when both are placed together in the final composition, the material object now has an immaterial, metaphysical presence one could identify as soul. In this paper, I present a recent artwork that exhibits these characteristics, and the theme of Reality, Truth and Lie is firmly placed within the current political context. The historical background to my work, relevant aspects of the technical process, and closer analysis of the ambiguities inherent in the hologram are all noted in my narrative, and I add my own personal comments and opinions. One invaluable source has been the published accounts of other artists/holographers who describe their own experience in holography, a medium that fuels ideas rather than being only a tool to express them.
\end{abstract}

Keywords: holography; narrative art; metaphysical; perception; illusion; political art; mixed reality

\section{Introduction: A Pre-Holography Context}

In my practice I interweave reality and illusion, truth and lie. I favor the illogical, the primitive, and the mysterious-facets of our existence that oppose the rational and the material. The holographic image is a sculptural entity, a volume of light that occupies space. It is fragile, fleeting, transparent, and weightless; it embodies both the physical reality of the original object and its altered, transcendent state. The hologram is, in effect, both the Real and the Abstract, the body and the soul (Figure 1).

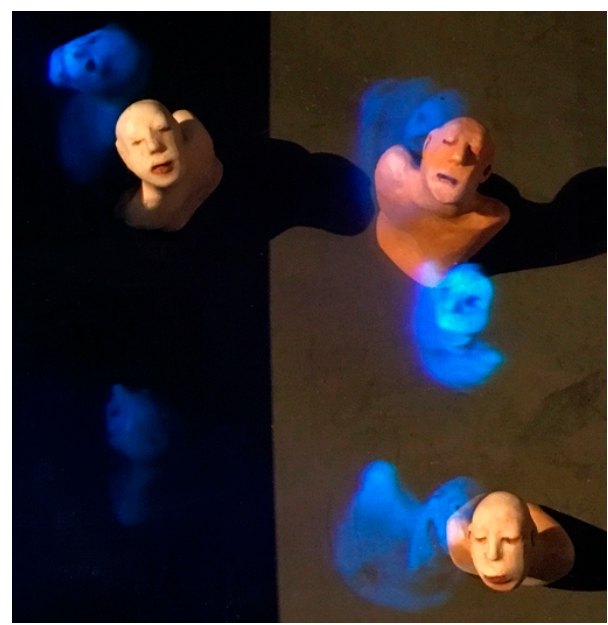

Figure 1. Anthropos (2017-18) holograms (blue), clay figures. Detail of work in progress. 
The artworks I made in the 1980s included three-dimensional assemblage that displayed little regard for longevity or collectability, as actual process was what mattered, not the end-product. This approach to making sculptural art was in keeping with the Process Art movement (Artspace Editors 2013) of the sixties that evolved into post-minimalist "sculpture-in-the-expanded-field", as art critic and theorist Rosalind Krauss (1979) described it. Certain aspects of the movement appealed to me, such as the use of unorthodox materials and the anti-market stance, but I could not accept the call to dematerialize the art object (Lippard 1970) and embrace a conceptual art that depended upon thought and theory alone and not the physical craft of work made by hand. Examples below illustrate two of my early works created with materials similar to those I use in holography today, especially the box format. They also reflect the beginnings of an exploration of themes based on personal experience. I did not actively seek political or social issues for these themes; they entered my life uninvited, as they still do now. In 1967, during the Vietnam War, my husband and I chose to disregard his U.S. military draft notice and we moved from Ohio to Canada. Within the practice of art, as with life, sometimes difficult decisions must be made, and it is necessary to let the Muse guide us.

Woman in White (Figure 2) was one of a series of boxes containing xerox-printed photos and small objects embedded between the transparent layers. A space existed between the transparencies, so when the viewer moved in for a closer look, a shift in spatial relationships caused a slight stereoscopic effect which rendered the image as having volume and even an impression of movement. This is my interpretation of the piece: White is the innocence of my First Communion dress when I reached the age of reason, my nursing uniform, my wedding dress inside a burial piece I created for it on a Lake Ontario beach, and white is the Shroud of Death. This work recalls Dicken's Miss Havisham in her attempt to freeze time and return to the past, something neither she nor I could do.

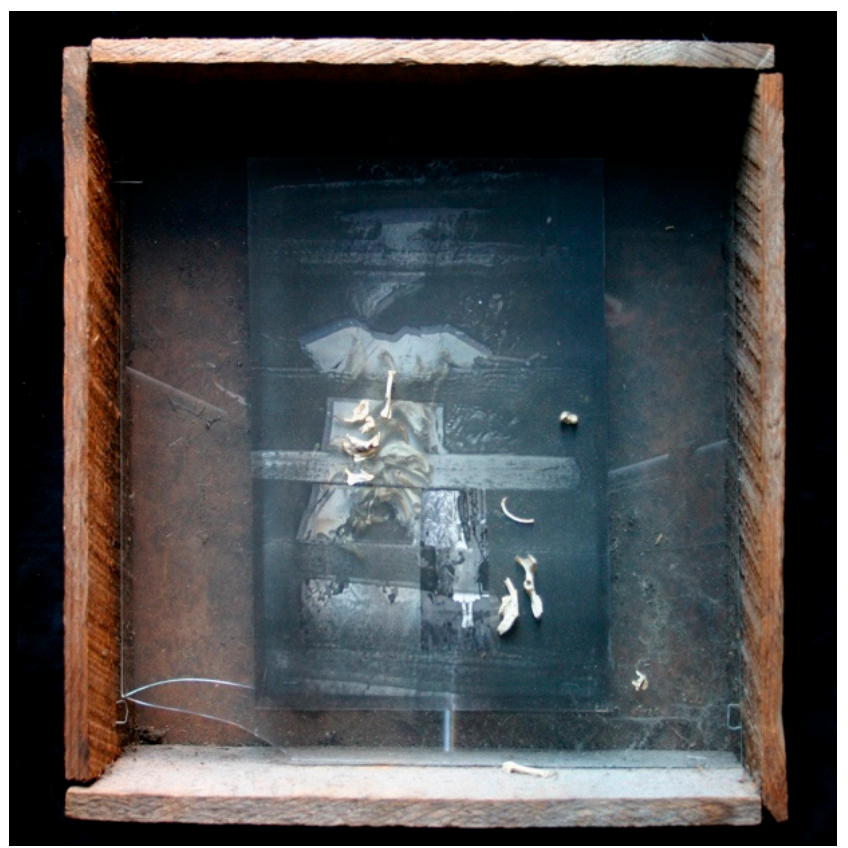

Figure 2. Woman in White (1980). Found box, dust, photos, spider webs, and mouse bones.

The second work Replica (Figure 3) has none of the structural elements of Woman in White, but thematically arises from the same intention, an exploration of reality and illusion, this time using painted trompe-œil. As a studio painter, I often used my own photos as reference for painting landscapes, these being my ideal, ordered version of the world. Walter Benjamin's essay Art in the Age of Mechanical Reproduction gave me a theoretical understanding of the idea of the original and its copy, but what would a large replica of an object look and feel like so I could compare? I found an old door in Toronto street garbage, thinking at least it would be a good exercise in matching paint 
color. I then attempted to accurately reproduce the door not only as a painted image but as a painted object. Something unexpected happened in that process that influenced the course of my practice. When I finished and took a fresh look at both door and canvas together, I experienced what I can only call simultaneity. Here were two opposing realities, two states of being, visible together in real time. It was as if a crack appeared in my world, and I had stepped into it. Was that the experience of art? Or perhaps I finally understood a paradox of physics, that matter and energy, body and spirit, could coexist in the same space. This may have been the beginning of my work in holography, or at least the spark that would later ignite the flame.

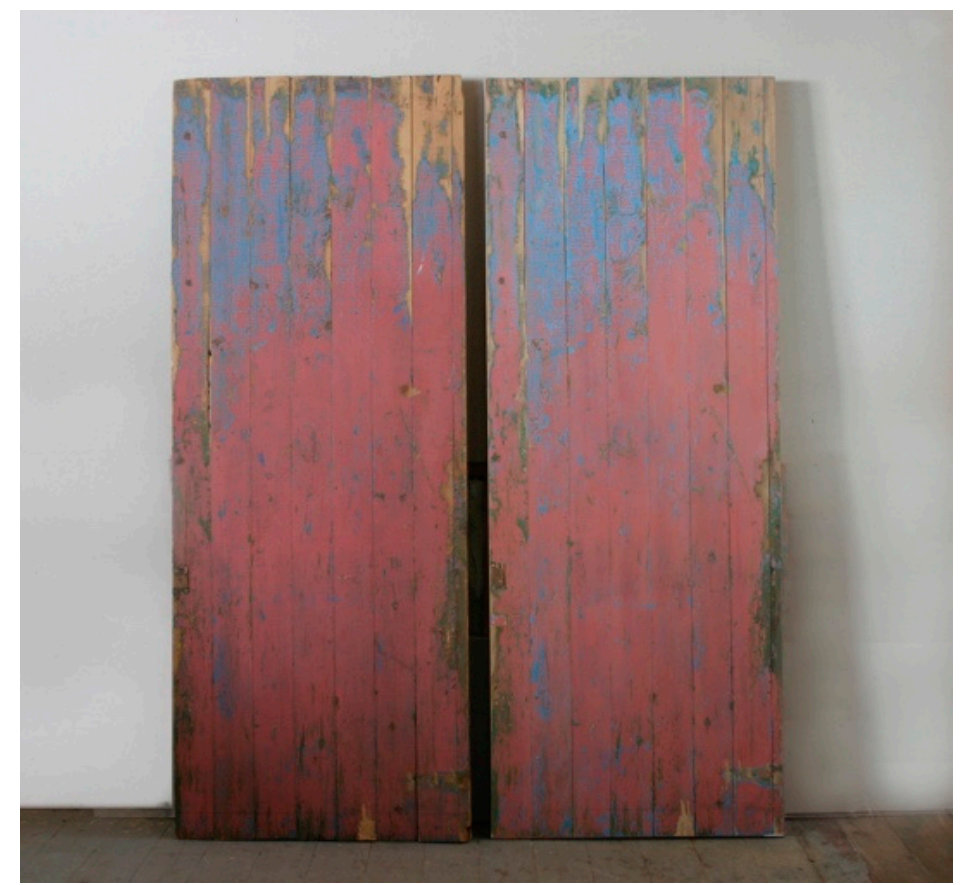

Figure 3. Replica (1982). Found door (left) with painted canvas (right), each panel $63 \mathrm{~cm} \times 165 \mathrm{~cm} \times 4 \mathrm{~cm}$. Collection Butler Institute American Art, Youngstown, Ohio, USA.

\section{Entering the Holo Zone}

I saw my first hologram around 1983 in Toronto; I do not remember the exact venue, but the image has stayed with me for more than thirty years. Portrait of Lad (1982) by Canadian artist Stephen Cruise ${ }^{1}$ was a hologram of a small transparent meditating Buddha, his internal rib cage and bones visible in the hologram. This image that hinted of other immaterial dimensions inspired me to master the medium. Cruise recently provided me with details; he produced it at Fringe Research Holographics in Toronto, a lab and exhibition space (Interference Gallery) that was run by artists David Hlynsky and Michael Sowdon. Cruise writes: "At the time the set-up to produce the hologram was the Whole Earth Catalogue method, a big sandbox on inner tubes and mirrors glued to PVC pipes. We did it in the early hours between the passing of the King St. streetcars-their vibrations gave us no picture. I was fresh back from four years away (Korea and Japan) with a pile of sketch books (drawings and collages, one done every other day) and continuing zazen from my practice/study in Tokyo of Soto Buddhism with Nishijima Sensei." Cruise added an aside in this email to me: "Just googled Fringe Research—it's the name of a hair salon in the same building at King and Dufferin." ${ }^{2}$

http://www.stephencruise.com (accessed on 6 July 2019).

Cruise, email correspondance. 6 July 2019. 
After a few workshops and artist-in-residencies, I felt prepared to work on my own. In 1990, at artist Doris Villa's Hope Street lab in Brooklyn, the holograms I made from small plaster and clay objects reflected a change in my practice, and for a month I worked day and night, sleeping in a corner of the lab, immersed in this new direction.

\section{Exploring Attributes of the Medium: Navigating the Maze of Possibilities}

The master/transfer method of making a hologram results in a clearly defined image if recorded from carefully chosen models, and the process offers some flexibility in the lab for positioning this object in space or making color adjustments. During the next stage of building the mixed-media environment, other perceptual elements can be manipulated for additional illusory effects.

The holographic element in Figure 4 floats above the physical bone, behind the plumb line but in front of the photo of the hallway on the back wall, on the same plane as the "economy" plaque. This secondary illusion of distance extends the space, presenting the viewer with another ambiguity and a reminder that photos do not always represent truth. In Figure 5 the holographic image is still behind the image plane, but the figure appears to be behind the photo of a window in the brick wall; a perceptual illusion re-enforced by the viewer's preconception that the figure must be part of the photo and could never be floating in front of the building.

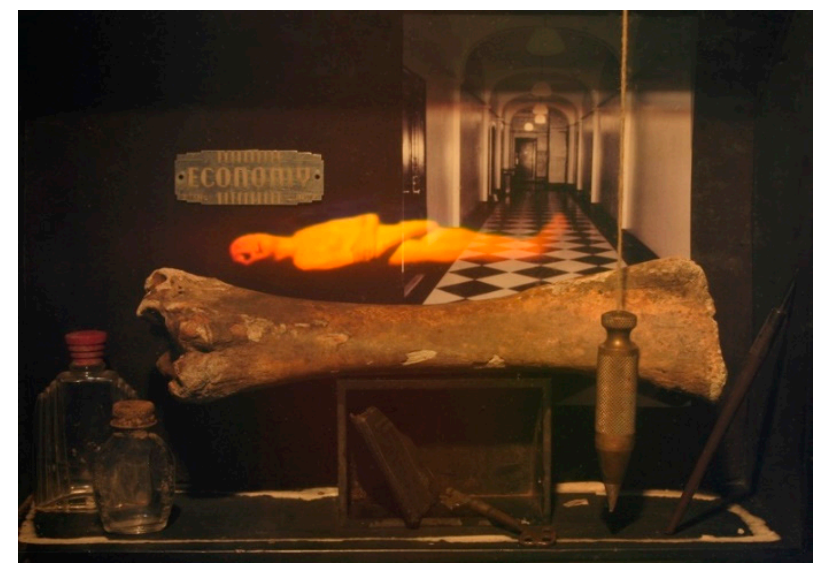

Figure 4. Economy Box (1992), $43 \mathrm{~cm} \times 33 \mathrm{~cm} \times 12 \mathrm{~cm}$

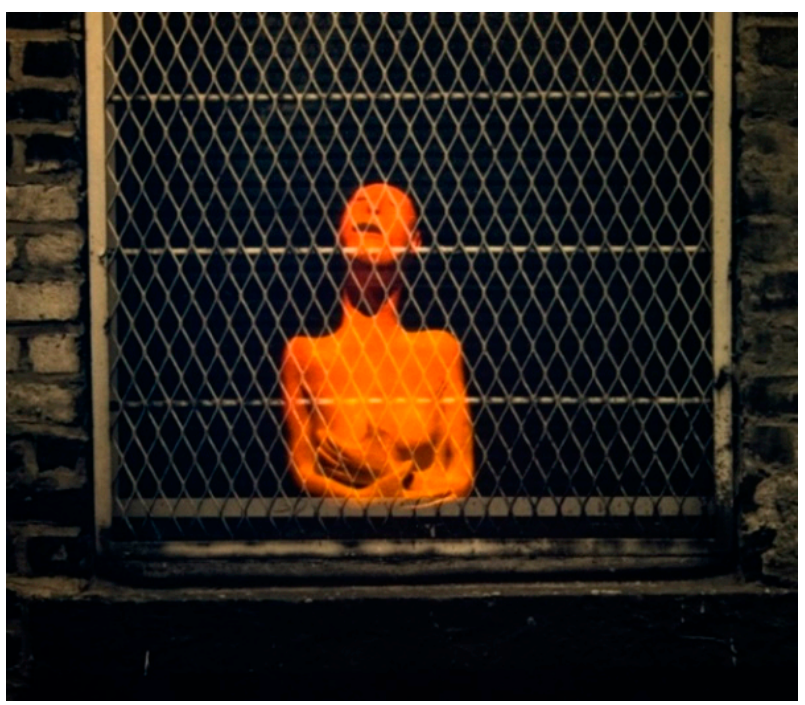

Figure 5. Hope Street (1990), $30 \mathrm{~cm} \times 20 \mathrm{~cm}$.

Artist Martin Richardson noted these visual ambiguities in his own mixed-media work when he combined holograms with photos and actual objects in the same space. He writes: "the holograms 
provide an illusion of space receding beyond the actual plane of the framed glass; this is immediately countered by the flatness of the photographic image." He notes how the viewer will accept the content as 'possible' and finally will accept the illusion. "Needless to say," Richardson adds, "many viewers find this acceptance troublesome. People often reach out and touch holograms to test the reality of their vision" (Richardson 1987). When confronted with opposing facts and ambiguities, viewers either learn to look closer and think about what they are actually seeing or simply choose to ignore disturbing situations as "troublesome".

Public understanding and acceptance of the illusion of holography is less an issue than it was even a decade ago. Both technical and artistic quality of the work has improved, and gallery and museum curators recognize that promoting holography as a medium of light places it in the context of artists James Turrell and Dan Flavin. What an artist deems as art, and whether the public accepts it as art, is dependent on the current value system of the culture in which they live. Art historian Alex Potts (2000) notes that when Neoclassical sculpture of the 18th century was introduced to viewers accustomed only to a two-dimensional pictorial space (which included sculptural relief), they could not adapt to walking around and observing the new three-dimensions. Potts provides a full account of, and a reason for, a very negative public response: aesthetic appreciation was so intimately linked to the formal organization of the artwork that beauty could only be recognized in two-dimensional works with a formal pictorial space. A heap of marble in the middle of the room was ugly and having to walk around this so-called art was a further assault on one's sensibilities. Holography may have survived the kitsch-stage in its development, but there still may be the bias as expressed by artist Eduardo Kac (1990): "Holographic art will only earn the consideration it deserves when trained and untrained observers alike can look at a hologram and not be haunted by spirits, specters, apparitions, phantoms, and other supernatural beings of critical discourse". Kac's article is an excellent source for understanding illusion and representation in holography, but it is my view that an artist can use this powerful element metaphorically as a positive force. Whether a work is seen as art or craft is not my concern, and if the "untrained observer" finds delight in the holographic image, that alone may be enough to lead to further thought, further questions.

I am aware of the implications of describing my holographic images as having soul or another dimension; we have not yet found-or possibly lost - the words to describe that part of our nature. There have been times in history when people believed in gods and the afterlife, when painted illusions and the possibility of other realms of existence were accepted. Near Pompeii, Roman Second Style frescoes give the illusion of an exterior garden, complete with walls and openings. There is one theory that because these illusions are painted only on bedroom walls, their function may have been to allow the sleeper to access another dimension-the world of the dead. There is two-way traffic; the spirits of the deceased could enter the rooms and dreams of the living (Owen 1989).

Transitional States (Figure 6) contains some of the holograms from my Hope Street Series. The tone is meditative and dream-like, and the title refers to an electron's quantum leap from one energy level to the next. The final artworks are intimate metaphysical worlds viewed through windows, fragile beings suspended in space, and lost souls in transition. Artist Shunsuke Mitamura spoke of the aura of the hologram that encompassed his experience of working in this medium, "I feel that the creation of the universe, the big bang, corresponds in holography to the moment of meditation in a darkroom when everything stops and the shutter is pressed." Mitamura (1989) views holography not only as an image-making process but that it also functions as a source of ideas, as an "image-stimulating mechanism." He confesses, "I secretly refer to this process as 'holosophy' a compound of 'holography' and "philosophy'". The hologram, if used by the artist in a manner that reflects his or her philosophy and experience of life, comes close to Art's origin and essence. We are transient, fallible creatures, and our souls pause for a moment in the journey to scratch those marks that affirm the only truth that one can know for certain: I exist. From writer Gabriele Guerico:

Whenever we look at an artwork and try to envision the dimensions of life embedded in its images and form; whenever we think of an artist as a concrete individual as well as a presence 
in his or her work; whenever we conceive of artistic phenomena as manifesting living qualities and unfolding a sense of humanity, singularity, and identity in the making, we enter into a moment of consciousness in which and for which art is revealed vis-à-vis existence. (Guerico 2006)

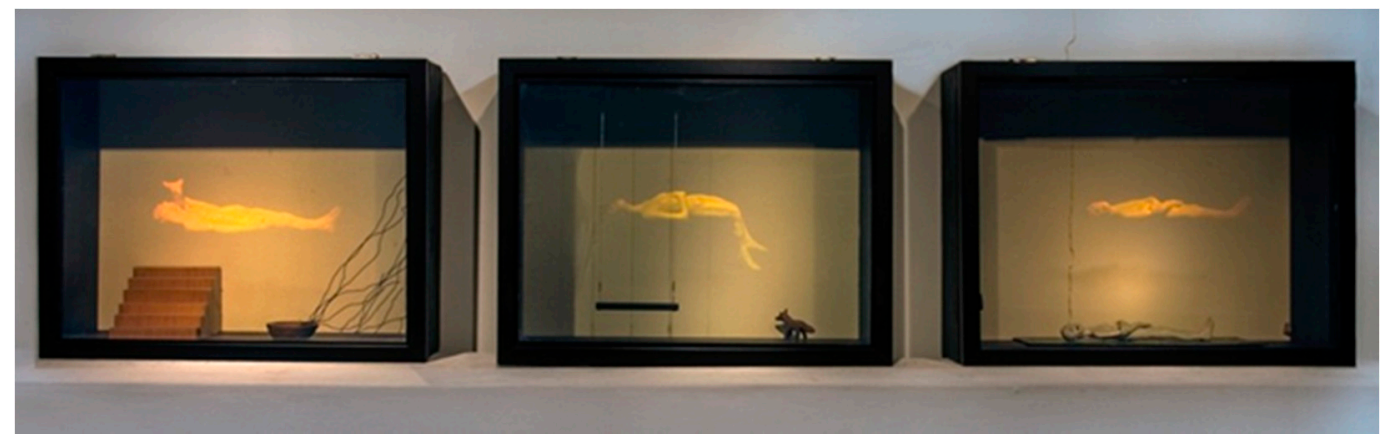

Figure 6. Transitional States (2009). Three holograms, each box $43 \mathrm{~cm} \times 33 \mathrm{~cm} \times 12 \mathrm{~cm}$.

\section{Returning to the Source: Creating the Original Models}

I began making clay figures in the early 1990s, when I worked as a nurse in a hospital in Arizona, just before the start of what the Americans called Operation Desert Storm. The deadline for withdrawal of Iraqi forces from Kuwait had come and gone, and the bombardment began. Televisions carried the play-by-play in the hospital rooms as I went about caring for my patients, and on days off I went to the galleries in Scottsdale to look at art. One day I stood before a small sculpture of a naked man crawling out from a hole in a mound of clay. It was an artwork based on a Hopi creation myth that we are living in the Fourth World, on the threshold of the Fifth. In each of the three previous worlds, humanity was destroyed by destructive practices and wars. In one Native American version, ours is now the Final World.

The lying figure (Figure 7) with one arm crossed over its body had characteristics similar to the Greek Cycladic figurines. Made of inexpensive materials, they functioned as votive objects and as gifts in social occasions. Following this tradition, I cast plaster multiples that became my muses; they sat on windowsills in the sun or lay hidden in a friend's pocket, an amulet that gave comfort to the hand that reached in to hold it. Others were made of clay and fired, and if I wanted to make changes, I made a plaster copy from a mold and recast it. This all took time, and the figures acquired personalities; a hologram made from one of my little people was not merely a copy of a static form. The final transformation of the figure into the holographic image added an ephemeral element to the original object when I placed them together. Through the interface of object and its virtual counterpart, the original was enhanced; it now appeared to have soul. The effect was best described to me in a more technical manner by artist/holographer/friend Jacques Desbiens:

The hologram creates a presence but no substance, except as light and meaning. This object/image ambiguity is fundamental in holography because it creates a tension between real and virtual far more obvious than with any other medium; it is found in many holographic artworks. On the other hand, within your containers and boxes, the illusory images are associated with the real object. Material object + light object. So all objects become ambiguous. ${ }^{3}$

3 Desbiens, Jacques. Personal email correspondence. 29 March 2019. 


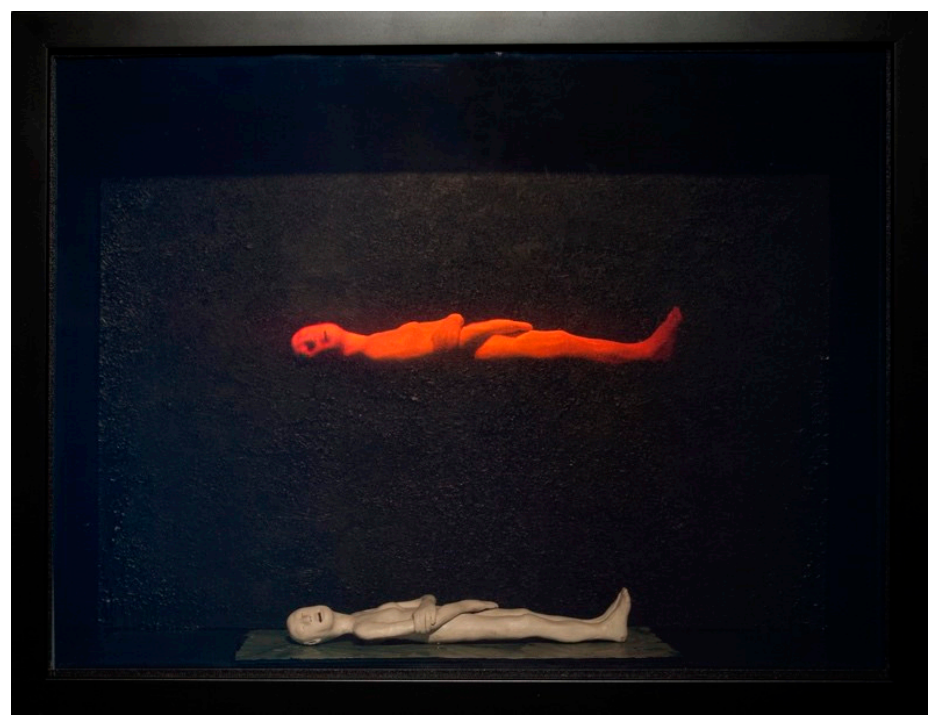

Figure 7. Body and Soul (2008). Reflection hologram, in box with model, $40 \mathrm{~cm} \times 30 \mathrm{~cm} \times 10 \mathrm{~cm}$.

\section{Anthropos: A Final Artwork}

In Anthropos (Figure 8), actual figures interact with immaterial holographic ones. The merging of these two states, reality and non-reality, creates an environment all too familiar to an observer of the current American political climate. Anthropos is a roman à clef, a story with a metaphorical key, a political representation with irony in the spirit of traditional commedia dell'arte.

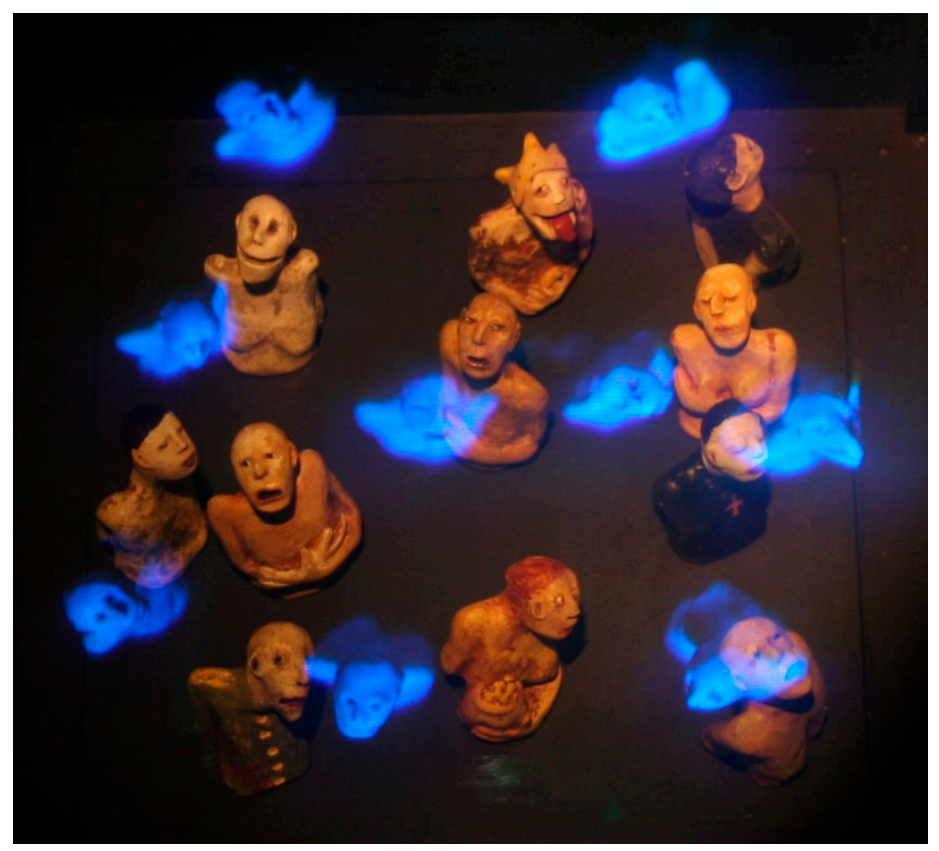

Figure 8. Anthropos (2017-18), reflection hologram, metal box, $25 \mathrm{~cm} \times 25 \mathrm{~cm} \times 10 \mathrm{~cm}$, clay figures $6 \mathrm{~cm}$.

Inside the metal container, a vintage US Army Ration Kit, there are 10 terracotta figurines and 10 holographic ones. The models for the holograms were clay figures that are allegorical representations of death, one being the danse macabre of the middle ages. The cast of blue holographic characters are all smiling and playful, as if enjoying some great cosmic joke at the expense of the mortals. My point of reference was the description of daimones by the Greek poet Hesiod in Works and Days (700 BC); these spirits were sent by the gods to keep watch over human beings to prevent them from doing evil. 
The word anthropos literally implies one who is capable of higher thought and could attain the state of

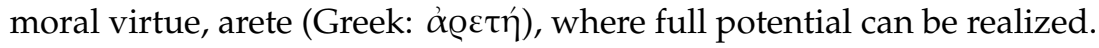

Using my clay figures, artist August Muth and his team at The Light Foundry in Santa Fe produced two holograms, and both were installed the following month (June, 2017) at the annual Currents New Media Festival in Santa Fe, New Mexico. My primary intention in exhibiting is an artistic one, to present an effective use of the medium; this was a rare opportunity to present art that referenced a current political concern and to exhibit it so quickly. This meant that viewers could more easily make the connection between the artistic fiction and the reality of the American political scene.

In the first version, the actual figures in the box are the same ones that were used to create the holograms, so they were visually similar. After I had the hologram in hand and Donald Trump had been in office for a year, I made new clay figures which offered a stronger contrast to the holographic images and in turn strengthened the metaphors. The painted figures were personifications of greed, lust, and power. The archetypes included the General, the Church, and the Fool, who, in the medieval Saturnalia, becomes King when the world is turned upside down. The work Anthropos references many sources of political theatre and art with a moral message, including a Brueghelian Last Judgment with overtones of the Seven Deadly Sins. Concurrently, I made a small series of paintings that reflected the confusion, anger, and fear evident in the rallies during the presidential campaign and its aftermath, and two of these were exhibited as a diptych next to the hologram Lost Souls for the exhibition (see Figure 9).

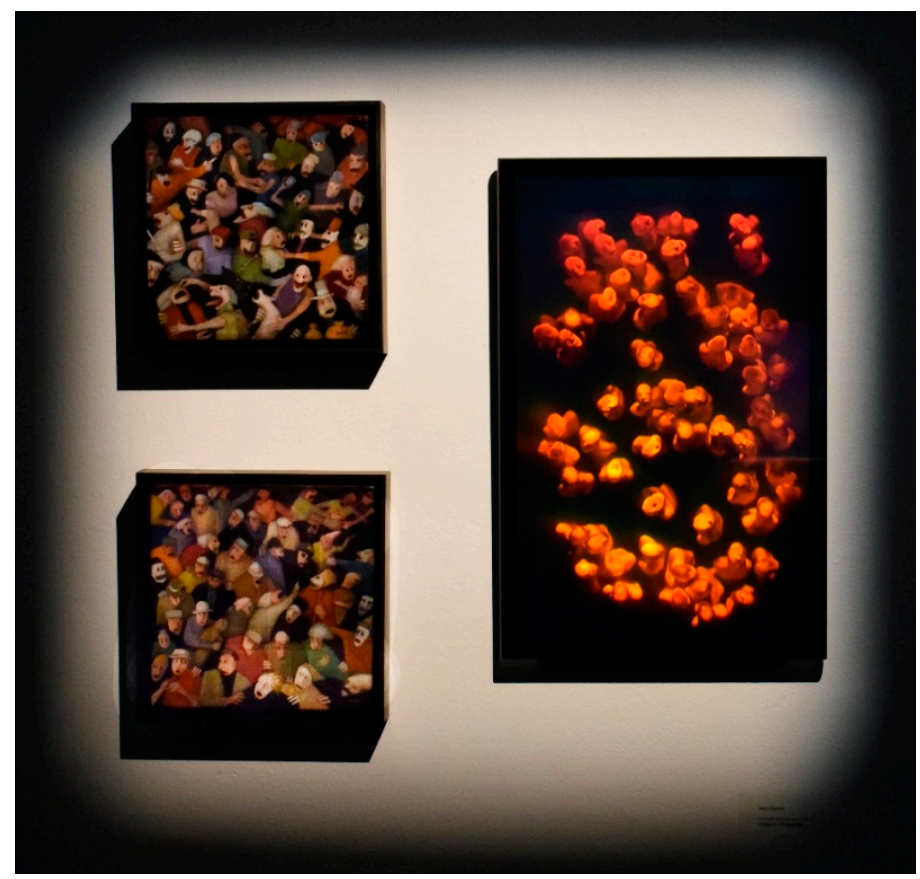

Figure 9. Installation view, “Currents New Media” (2017), Santa Fe, New Mexico. Left: Civil Discourse (2016-17), two acrylic paintings on wood panels each $25 \mathrm{~cm} \times 25 \mathrm{~cm}$. Right: Lost Souls (2017), Dichromate Gel (DCG) hologram, $46 \mathrm{~cm} \times 30.5 \mathrm{~cm} \times 5 \mathrm{~cm}$. Photo used with permission of The Light Foundry, Santa Fe, N.M.

The final hologram in this series, Lost Souls (Figure 9), features multiple holographic figures looking up from an enclosed space. There are no actual objects, only dream-like virtual images that shift positions and change color as the viewer walks by them. They are the lost souls, collateral damage of our times, an era of intolerance, power, greed, and inhumanity. This artwork acknowledges their presence and records their passing.

In conclusion, artist Ai Weiwei gives us a definition of art that is fitting for our time:

Art is a social practice that helps people to locate their truth. (Ai 2019) 
Funding: This research received no external funding.

Acknowledgments: All photos created by author unless noted in text.

Conflicts of Interest: The author declares no conflict of interest.

\section{References}

Ai, Weiwei. 2019. Every Day We Put the State on Trial. Available online: http://creativetimereports.org/2013/04/15/ china-every-day-we-put-the-state-on-trial/ (accessed on 26 May 2019).

Artspace Editors. 2013. An Introduction to Process Art. Available online: https://www.artspace.com/magazine/art_ 101/art_market/process_art-51778 (accessed on 11 July 2019).

Guerico, Gabriele. 2006. Art as Existence: The Artist's Monograph and its Project. Available online: https://www.academia.edu/4064892/Marjorie_Och_review_of_Gabriele_Guercio_Art_as_Existence_ The_Artists_Monograph_and_Its_Project_Renaissance_Quarterly_60_3_2007_919-21 (accessed on 11 July 2019).

Kac, Eduardo. 1990. Photonic Webs in Time: The Art of Holography. Available online: http://www.ekac.org/ photonic.webs.isea_95.html (accessed on 12 July 2019).

Krauss, Rosalind. 1979. Sculpture in the Expanded Field. "Front Matter". October 8: 1-2. Available online: http://www.onedaysculpture.org.nz/assets/images/reading/Krauss.pdf (accessed on 8 July 2019). [CrossRef]

Lippard, Lucy. 1970. Six Years: The Dematerialization of the Art Object from 1966 to 1972. Berkeley: University of California Press.

Mitamura, Shunsuke. 1989. Holographic Holography. Leonardo 22: 337-40. [CrossRef]

Owen, Maurice. 1989. The Spirits Released-De Chirico and the Metaphysical Perspective. Available online: http://creadm.solent.ac.uk/custom/artresearch/dechirico/text/spirits_11.html (accessed on 26 May 2019).

Potts, Alex. 2000. The Sculptural Imagination: Figurative, Modernist, Minimalist. New Haven: Yale University Press. Richardson, Martin. 1987. Mixed Media: Holography Within Art. Leonardo 20: 251-55. [CrossRef]

(C) 2019 by the author. Licensee MDPI, Basel, Switzerland. This article is an open access article distributed under the terms and conditions of the Creative Commons Attribution (CC BY) license (http://creativecommons.org/licenses/by/4.0/). 